\title{
潜 血食について \\ On the Study of Control-Diets in Occult-Blood Tests
}

大阪府立病院 給食係

(Osaka Prefectural Hospital)

町田三慈江

(Michie Machida)
長島智恵子

(Chieko Nagashima)

研 究 検 査科

福 本 紘一

(Koichi Fukumoto)
梶田知道

(Tomomichi Kajita)
村 田 吉 郎

(Yoshio Murata)

In despite of the improved procedures of the occult-blood tests of feces, the dieticians frequently meet some difficulties in preparing a menu for the patients, because it is very important to control diets prior to these tests. Some of the vegetables, which are boiled more than thirty minutes, are proved to be available for this purpose. The foodstuffs, which might cause a false positive reaction unspecificially in the tests, should be excluded from this menu. In this experiment, the authors reexamined the influences of cooking for occult-blood tests, using the 68 vegetables and 28 meats, and attempted to magnify the materials in the list of control-diets.

Four methods are employed as occult-blood tests; Hematest B, Benzidine test (Adler), Pyramidone method (Adler) and Guajac method (Deen). The occult-blood test, in vitro, are carried out on each food material before and after cooking. The same procedures are done on the feces of healthy volunteers with the same materials. The number of false positive vegetables in all vegetables is markedly reduced after three minutes' boiling. The same result of decrease is obtained on the feces with boiled vegetables, being more prominent in degree than on fresh vegetables only. These results, however, are not obtained on the meats.

The present data shows that the control of diets and the method of cooking previously employed for the occult-blood tests are too much exaggerated.

\section{緒言}

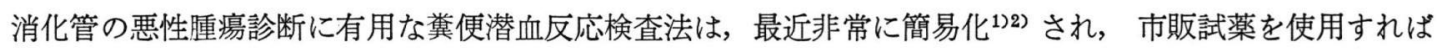
検査担当者に高度の熟練を要求せずしかも迅速正確な判定が可能となってきた。

しかし検査原理は依然として Peroxidase の作用による酸化を利用するため, 非特異的にヒト血色素以外を も検出する欠点を有している。そこで臨床的には試薬種類および反応感度の異なる二, 三の検査法を併用し, 
結果を総合判定する必要がある。また非特異偽陽性反応を呈する食品類を除去した制限食事 “潜血食”を数日 間被検者に強制することになる。

この禁止食品類は成書にもあるが，in vitro 実験であり，献立作成困難な程度の制限であるなどから，著者 らは実状に即した禁止怙よび許容食品の決定を試み，90余種の食品につき,数種の潜血反応を行ない，in vivo の検討をも行なったので報告する。

\section{研 究 方 法}

1. 使用した潜血反応検査法抒よび食品

Hematest 法 (Ames 社), Benzidine 法 (Adler 法), Pyramidon 法 (Adler 法)。

Guajac 法 (Deen 法), (以下 $\mathrm{H}, \mathrm{B}, \mathrm{P}, \mathrm{G}$ 法と略す)。食品は表 1 に示す。

表 1 組合わせ実験使用食品類

\begin{tabular}{|c|c|}
\hline 群 & 品 \\
\hline 陰 性 食 & 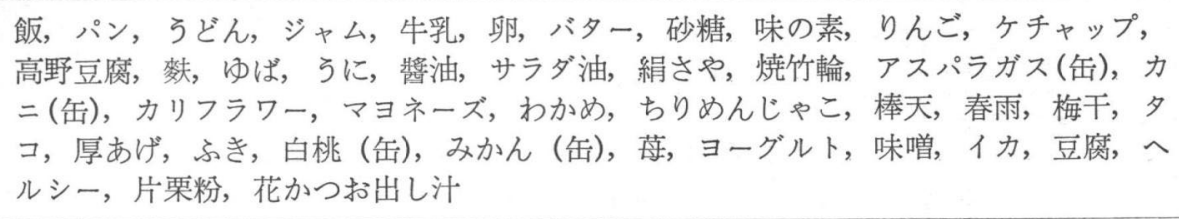 \\
\hline $\mathrm{A}^{1} \quad$ 食 & ほうれん草, 人参, 長芋, 胡瓜, 大根, キャベッ, 白菜, 芽キャベッ, 大和芋, ゴマ \\
\hline $\mathrm{A}^{2}$ 食 & $\begin{array}{l}\text { バナナ, えのき茸, 青菜, トマト, セロリ, しいたけ, 京菜, みつば, うど, 浅草のり } \\
\text { ビゃがいも, 白菜浅漬, ニラ, レモン }\end{array}$ \\
\hline $\mathrm{A}^{3} \quad$ 食 & $\begin{array}{l}\text { ハッサク, ニューヨークレタス, 青葱, 南瓜, 玉葱, さつまいも, 千切大根, 昆布, 里 } \\
\text { 芋, サラダ菜 }\end{array}$ \\
\hline $\mathrm{A}^{4} \quad$ 食 & もやし, グリンピース, 茄子, 小麦粉 \\
\hline $\mathrm{B}^{1}$ 食 & ひらめ, えび, かまぼこ \\
\hline $\mathrm{B}^{2}$ 食 & 鯛，ハモ, サワラ, 花かつお，鰺，マグロ \\
\hline $\mathrm{B}^{3}$ 食 & マス, 梅焼 \\
\hline $\mathrm{B}^{4}$ 食 & 牛肉, 八厶, 焼豚, 鷄肉, 牛肉大和惹（缶） \\
\hline
\end{tabular}

\section{2. 各種潜血反応検査法の陽性限界決定}

健康人抗凝固剂添加血液 (赤血球数 $455 \times 10^{4}, \mathrm{Hb}$ 量 $14.7 \mathrm{~g} / \mathrm{dl}$ ), の倍数稀釈系列を作り, 上記 $\mathrm{H}, \mathrm{B}, \mathrm{P}$, G 法の陽性限界を決め以下の検討に用いた。

3. 潜血反応の出現と加熱による変化（in vitro 実験）

各食品 $10 \mathrm{~g}$ を可食部各所より平等に取り内 $5 \mathrm{~g}$ は生のまま乳鉢で粉砕し, 残部 $5 \mathrm{~g}$ は, $100 \mathrm{ml}$ の水中に入 れて $100^{\circ} \mathrm{C} 3$ 分間煮沸後, 粉研する前処理を施し, 生食品と加熱食品について各種潜血反応検查を行なった。

\section{In vivo 実験}

(a) 組合わせ食品実験

In vitro 実験で，生食品が B 法以外の 3 法で陰性であった食品を陰性食群とし，また B 法以外に陽性であ った食品を便宜上表 1 に示す 9 群に分けた。次に健康喫食者 13 名を選び，図 1 の計画に従って試験食 1 群 3 
ないし 4 名の割て同一食群に限った献立を喫食させ，延 173 回の粪便潜血反応を行ない, 各試験食群食品陽性率 を判定した。

(b) 単品喫食実験

上記実験て陽性となった試験食群の食品は 1 種類ずつ を単独に陰性食群と組合わせた献立表により健康人 45 名 に喫食させ，同様に潜血反応を行なった。
図 1 組合わせ食品喫食実験

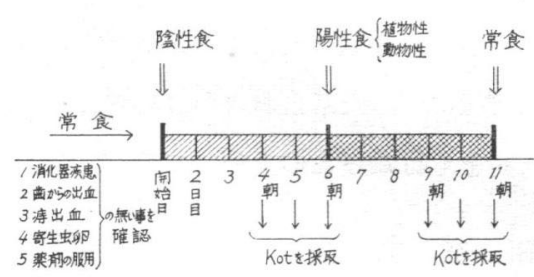

表 2 生食品と加熱食品の潜血反応（in vitro）〔その 1]

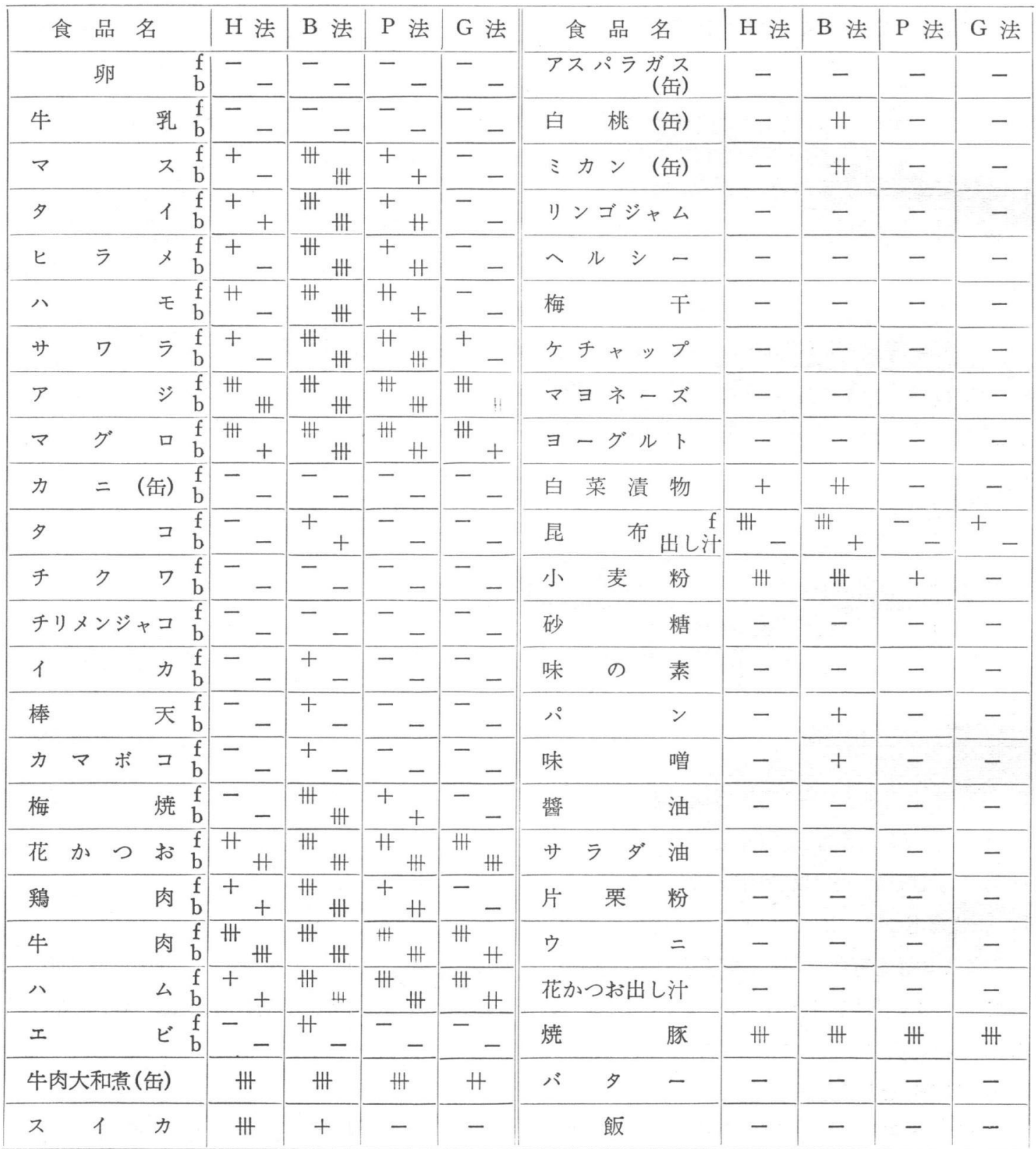




\section{結果および考察}

\section{1. 潜血反応の陽性限界}

B 法では $512 \times 10^{3}$ 倍て始めて呈色したものを陽性 $(+$ ）としその色調の強さによりそれぞれ (H)，（卅）と して表わし1分以上経過しても呈色しないものを陰性 (一) として表わすことにした ${ }^{374) 。}$ 以下同様にしてH法ては $128 \times 10^{3}$ 倍, $\mathrm{P}$ 法では $64 \times 10^{3}$ 倍, $\mathrm{G}$ 法 $32 \times 10^{3}$ 倍て始めて呈色した。

2. In vitro 実験

表 2 生食品と加熱食品の潜血反応（in vitro）〔その 2〕

\begin{tabular}{|c|c|c|c|c|c|c|c|c|c|c|}
\hline 品 & & H 法 & B 法 & 法 & G 法 & 食 品 名 & $\mathrm{H}$ 法 & B 法 & P 法 & G 法 \\
\hline ホウレン & 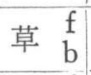 & 册 & Ht & - & - & ナン & + & + & - & - \\
\hline サ ラ ダ & 菜 $\begin{array}{l}f \\
b\end{array}$ & $H_{-}$ & H & - & - & グリンピース $\begin{array}{l}f \\
b\end{array}$ & $\mathrm{H}$ & $H_{H}$ & + & - \\
\hline キュウ & リ $\begin{array}{l}f \\
b\end{array}$ & $\mathrm{H}$ & + & - & - & シ イタ ケ $\begin{array}{l}\mathrm{f} \\
\mathrm{b}\end{array}$ & + & H & - & - \\
\hline アオ & $\begin{array}{ll}\text { 菜 } & f \\
b\end{array}$ & $\mathrm{H}$ & $\mathrm{H}_{H}$ & - & - & カリフラワー $\stackrel{f}{b}$ & + & - & - & - \\
\hline キャべ & y $\begin{array}{l}f \\
b\end{array}$ & $\mathrm{Ht}$ & ${ }_{H}$ & - & - & キ 又 $+\stackrel{f}{b}$ & - & + & - & - \\
\hline 白 & 菜 $\begin{array}{l}f \\
b\end{array}$ & $H_{-}$ & $H_{+}$ & - & - & サッマイモ $\stackrel{f}{b}$ & H & $H_{-}$ & - & - \\
\hline 京 & $\begin{array}{ll}\text { 菜 } & f \\
b\end{array}$ & $\mathrm{HI}_{+}$ & $\mathrm{HH}_{\mathrm{H}}$ & - & - & ト $\begin{array}{c}\mathrm{f} \\
\mathrm{b}\end{array}$ & $H_{-}$ & + & - & - \\
\hline 口 & リ $\begin{array}{l}f \\
b\end{array}$ & m & $H_{-}$ & - & - & 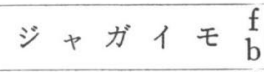 & - & + & - & - \\
\hline 夕 & ᄌ $\begin{array}{l}f \\
b\end{array}$ & m & Ht & - & - & $\vee \stackrel{f}{b}$ & + & H & - & - \\
\hline ネ & ギ $\begin{array}{l}f \\
b\end{array}$ & H & $H_{+}$ & - & - & ᄌ $\stackrel{f}{b}$ & $\mathrm{H}^{\prime}$ & $\mathrm{H}^{\prime}$ & + & - \\
\hline ッ & 葉 $\begin{array}{l}f \\
b\end{array}$ & \# & H & - & - & 1 チ $\exists \underset{b}{f}$ & - & - & - & - \\
\hline 芽キャべ & w $\begin{array}{l}f \\
b\end{array}$ & - & + & - & - & $\nu \quad € \quad>\stackrel{f}{b}$ & - & $H_{-}$ & - & - \\
\hline$=$ y & ข $\begin{array}{l}f \\
b\end{array}$ & $H_{-}$ & + & - & - & 高 野 豆 腐 $\stackrel{f}{b}$ & - & - & - & - \\
\hline 長 & 芋 $\begin{array}{l}f \\
b\end{array}$ & + & + & - & - & 腐 $\begin{array}{l}\mathrm{f} \\
\mathrm{b}\end{array}$ & - & - & - & - \\
\hline リ ン & $\exists \begin{array}{l}\mathrm{f} \\
\mathrm{b}\end{array}$ & - & + & - & - & バ $\underset{b}{f}$ & - & - & - & - \\
\hline パ ナ & $+\begin{array}{l}f \\
b\end{array}$ & + & ${ }^{H}$ & - & - & 雨 $\begin{array}{l}\mathrm{f} \\
\mathrm{b}\end{array}$ & - & - & - & - \\
\hline I, & $\begin{array}{l}\mathrm{f} \\
\text { 茸 } \\
\mathrm{b}\end{array}$ & + & + & - & - & 䴮 & - & + & - & - \\
\hline 大 & 根 $\begin{array}{l}f \\
b\end{array}$ & m & - & - & - & 千 切 大 根 $\stackrel{f}{b}$ & m & H & - & - \\
\hline 夕マネ & ギ $\begin{array}{l}f \\
b\end{array}$ & $H_{-}$ & + & - & - & 厚 ア & - & - & - & - \\
\hline 7 & $\neq \begin{array}{l}f \\
b\end{array}$ & - & - & - & - & ド ข $\stackrel{f}{b}$ & - & - & - & - \\
\hline २ & $\vdash \begin{array}{l}f \\
b\end{array}$ & m & + & - & - & 浅 草, リ $\mathrm{f}$ & ${ }_{H}$ & $\mathrm{H}_{\mathrm{H}}$ & - & - \\
\hline サ ト イ & $\epsilon_{b}^{f}$ & m & + & - & - & $\times \stackrel{f}{b}$ & - & - & - & - \\
\hline モ $\quad$ & シ $\begin{array}{l}f \\
b\end{array}$ & ${ }^{H}$ H & + & + & - & ラ $\stackrel{f}{b}$ & H & ${ }_{+}+$ & - & - \\
\hline ヤマトイ & $z^{f} \begin{array}{l}f \\
b\end{array} \mid$ & + & & - & - & ハッサク & m & $\mathrm{H}$ & - & - \\
\hline
\end{tabular}

f: fresh b: boil H 法: Hematest

B 法: Benzidine

P 法: Pyramidon

G 法：Guajac 


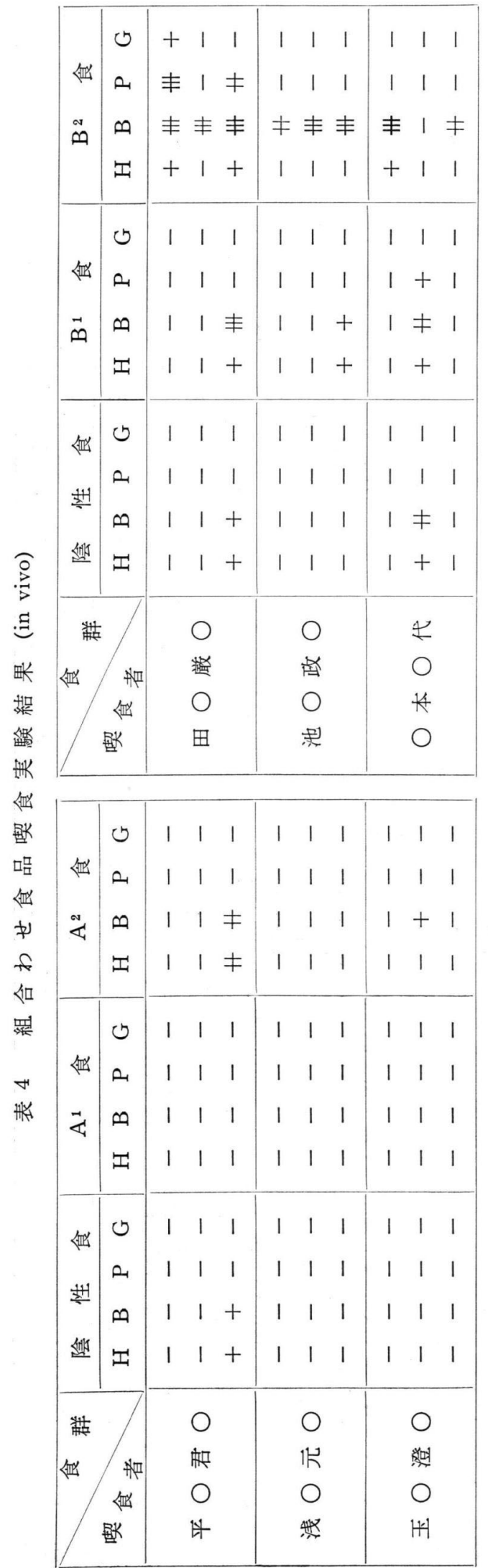

\begin{tabular}{|c|c|c|c|c|}
\hline 伤 & $\begin{array}{l}0 \\
0 \\
\infty \\
\text { D }\end{array}$ & $\begin{array}{l}\neq \neq \neq \neq \\
\neq \neq \neq \neq \\
\neq \neq \\
\neq \neq\end{array}$ & 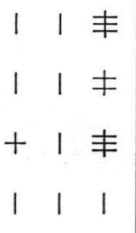 & $\begin{array}{l}\neq \neq \neq \\
\neq \neq+ \\
\neq \neq \neq \\
\neq \neq+\neq\end{array}$ \\
\hline 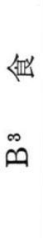 & $\begin{array}{l}D_{1} \\
\infty \\
\text { 出 }\end{array}$ & $\begin{array}{ccc}1 & 1 & 1 \\
1 & 1 & 1 \\
\neq & + & 1 \\
1 & \neq & 1\end{array}$ & 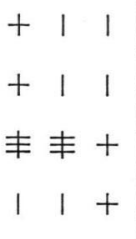 & $\begin{array}{ccc}1 & 1 & 1 \\
1 & 1 & 1 \\
+ & 1 & 1 \\
1 & 1 & 1\end{array}$ \\
\hline 近 & $\begin{array}{l}\infty \\
\infty\end{array}$ & $\begin{array}{ccc}1 & 1 & 1 \\
1 & 1 & 1 \\
+ & 1 & 1 \\
1 & 1 & 1\end{array}$ & $\begin{array}{lll}1 & 1 & 1 \\
1 & 1 & 1 \\
\neq & 1 & 1 \\
1 & 1 & 1\end{array}$ & $\begin{array}{lll}1 & 1 & 1 \\
1 & 1 & 1 \\
1 & \neq & 1 \\
1 & 1 & 1\end{array}$ \\
\hline & 佂 & $\begin{array}{l}4[ \\
0 \\
0\end{array}$ & $\begin{array}{l}0 \\
\text { 亪 } \\
0 \\
\text { 哏 }\end{array}$ & $\begin{array}{l}\bigcirc \\
\text { 测 } \\
\bigcirc \\
\equiv\end{array}$ \\
\hline
\end{tabular}

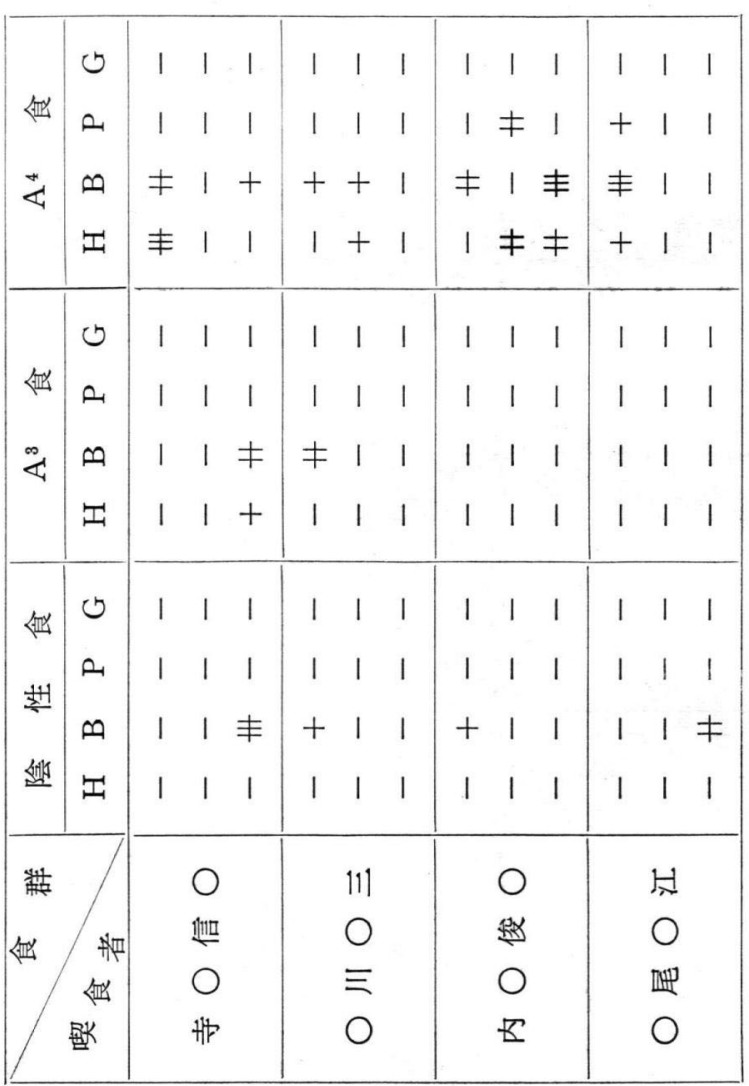


表 3 生食品と加熱食品の陽性率 (in vitro)

\begin{tabular}{|c|c|c|c|c|c|c|}
\hline \multicolumn{2}{|c|}{ 食 品 検 査 法 } & Hematest 法 & Benzidine 法 & Pyramidon 法 & Guajac 法 & 全 体 \\
\hline \multirow{2}{*}{ 物 } & $\mathrm{f}$ & 68.1 & 76.6 & 6.4 & 0 & ${ }^{*} 37.8$ \\
\hline & $\mathrm{b}$ & 10.6 & 44.7 & 4.3 & 0 & 14.9 \\
\hline \multirow{2}{*}{ 物 } & $\mathrm{f}$ & 47.8 & 78.3 & 56.5 & 26.1 & 52.2 \\
\hline & $\mathrm{b}$ & 30.3 & 60.9 & 52.2 & 21.7 & 41.3 \\
\hline \multirow{2}{*}{ 有 色植 物 } & $\mathrm{f}$ & 90.0 & 100.0 & 0 & 0 & ${ }^{*} 47.5$ \\
\hline & $\mathrm{b}$ & 10.0 & 70.0 & 0 & 0 & 20.0 \\
\hline 全食品偽陽性率 & $\mathrm{f}$ & 48.0 & 63.3 & 18.4 & 8.2 & 34.7 \\
\hline
\end{tabular}

$\mathrm{f}=$ fresh $\quad \mathrm{b}=$ boil

In vitro の生食品と加熱食品との潜血反応結果は表 2 の通りである ${ }^{5)}$ 。これは各食品の潜血反応出現と，そ の加熱による陰転の効果をみたものである。今これを植物性食品(加工品, 非加工品を含む) と動物性食品 (加 工品, 非加工品を含む）とに大別し各反応別に陽性率を計算してみると表 3 の如き結果になる。ここで各反応 別に加熱の効果をみると比較的感度の高いH法，B法に著しい陽性率の低下がみられる。これは試薬および反 応の化学構造上6) からも明らかなところである。また $\mathrm{P}, \mathrm{G}$ 法については陽性の生食品を加熱してもほとんど 陰性化することがない。しかも G法による植物性食品の潜血反応陽性率が “0”という事実は注目すべきであ る。G法で検査する限り粪便の潜血反応陽性の場合は確実に病的出血と考える7)，ということから植物性食品 を喫食させればほとんどその検査に食事の影響はないといえよう。

3. In vivo 実験

(a) 組合わせ食品実験

組合わせ食品実駼結果は表 4 の通りである。この表から各反応別, 食群別陰性率を計算し表 5 の如き判定 表を作成した。陰性食に掞ける反応別陰性率の数字は $95 \%$ 信頼限界の下限である。各食群の陰性率がこれを

表 5 判 定 表 (陰 性率)

\begin{tabular}{|c|c|c|c|c|c|c|c|c|c|}
\hline 反 応 群 & $\begin{array}{l}\text { 陰 } \\
95 \% \text { 性頼限食 }\end{array}$ & $A^{1}$ & $\mathrm{~A}^{2}$ & $\mathrm{~A}^{3}$ & $\mathrm{~A}^{4}$ & $\mathrm{~B}^{1}$ & $\mathrm{~B}^{2}$ & $\mathrm{~B}^{3}$ & $\mathrm{~B}^{4}$ \\
\hline Hematest 法 & $\sim 83.9$ & 100.0 & $\stackrel{8}{88.9}$ & $\stackrel{\circ}{91.7}$ & 58.3 & 66.7 & 66.7 & 77.8 & 33.3 \\
\hline Benzidine 法 & $\sim 67.4$ & 100.0 & ํำ & $\stackrel{\circ}{83.3}$ & 41.7 & 66.7 & 11.1 & 33.3 & 11.1 \\
\hline Pyramidon 法 & $\sim 91.2$ & $\stackrel{\circ}{100.0}$ & $\stackrel{\circ}{100.0}$ & 100.0 & 83.3 & 88.9 & 77.8 & 88.9 & 22.2 \\
\hline Guajac 法 & $\sim 91.2$ & i00.0 & $\stackrel{\circ}{100.0}$ & 100.0 & 100.0 & 100.0 & 88.9 & 88.9 & 22.2 \\
\hline \multirow{4}{*}{ 個 体 別 } & \multirow{4}{*}{$\sim 86.5$} & 100.0 & 100.0 & 83.3 & 75.0 & 83.3 & 33.3 & 75.0 & 0.0 \\
\hline & & 100.0 & 91.7 & 91.7 & 75.0 & 83.3 & 75.0 & 50.0 & 66.7 \\
\hline & & 100.0 & 83.3 & 100.0 & 41.7 & 75.0 & 62.5 & 91.7 & 0.0 \\
\hline & & - & - & 100.0 & 75.0 & - & - & - & - \\
\hline 全体の平均 & $91.0 \%$ & 100.0 & 91.7 & 93.8 & $* 70.8$ & 80.6 & $* 61.1$ & $* 72.2$ & $* 22.2$ \\
\hline
\end{tabular}


越えたものについて合格とし表中の数字の左カタに○印を付けて示した。しかしこれだけではたとえば $\mathrm{A}^{4}$ 食 の如く $\mathrm{H} ， \mathrm{~B} ， \mathrm{P}$ 法は不合格， G法合格となり判定にギャップが生じる。そこて下欄の如き食群別全体の陰性 率を求め, これと陰性食群全体の陰性率との間で検定を行ない有意に低いものに表中*印を付して示し不合格 判定の参考とした。 上記の判定基準によれば $\mathrm{A}^{1}, \mathrm{~A}^{2}, \mathrm{~A}^{3}$ 食群は in vivo で陰性食として合格となるが $\mathrm{A}^{4}$ 食群は不合格である。また $\mathrm{B}^{1}$ 食群はこの意味では合格であるが反応別にみれば 4 法中 3 法が不合格であるの で確実性を保持するため不合格とした。 $\mathrm{B}^{2}, \mathrm{~B}^{3}, \mathrm{~B}^{4}$ 食群はいずれも不合格となる。

要するに実験精度を落さぬ範囲で能率を上げるように判定基準を運用した。

(b) 単品喫食実験

食群全体として潜血反応陽性と判定した食群中の食品は 1 種類ずつを陰性食中に加え, 組合わせ実験と同様 喫食させた結果, $\mathrm{A}^{4}$ 食でモヤシ, $\mathrm{B}^{1}$ 食でヒラメ, $\mathrm{B}^{2}, \mathrm{~B}^{3}, \mathrm{~B}^{4}$ 食群はいずれも内容食品全部が不合格となった。 以上の結果から植物性食品については加熱することにより陽性率を著しく下げることができる。また加熱に よりたとえ陰性化しなくともこれを体内を通過させれば，モヤシなどの一部の例外を除いてほとんど潜血反応 検査に影響しないことがわかった。

動物性食品については加熱の効果はほとんどない。加熱により陰性化しない食品を in vivo て使用しても反 応が陰性になることは少ない。またこれを魚肉類と獣鳥肉類に分類した場合, 魚肉類の一部は使用てきるが, 獣鳥肉類については加工品, 非加工品を問わずその使用はほとんど不可能である。

なお組合わせ実験で合格としたカポチャ, ジャガイモ, カマポコ, ホウレン草については成書に不適の記載 があるものもあるため再度単品喫食実験を行なって陰性を確認した。

今回の実験で検討し得なかった点は, 生鮮食品については採取時期および採取場所, さらに加工食品につい ては製造所別の差異などである。これらは実駼結果に多少の変動を与えると考えられるが，全体としては著し い結論の変更はないと予想される。

また食品 1 品からの試料の採取は実験方法の項で述べた通りであるが, 献立常用量全部を粉研する方法も機 会を得て追加したいものである。以上より潜血食許可食品は表 6 に示した。

表 6 潜 血 食 許 可 食 品 例

飯, パン, ラどん, ジャム, 牛乳, 卵, バター, 砂糖, 味の素, りんご, ケチャップ, 高野豆腐, 䴳, ゆば, うに, 醬油, サラダ油, 絹さや, 焼竹輪, アスパラガス (缶), カニ (缶), 片栗粉, 花かつ打 出し汁, カリフラワー, マヨネーズ, ちりめんじゃこ, ワカメ, 棒天, 春雨, 梅干, たこ, ふき, 厚 あげ, 白桃(缶), みかん(缶), 莓, ヨーグルト, 味噌, いか, 豆腐, ヘルシー, ほうれん草, 人参, 長芋, 胡瓜, 大根, キャベッ, 白菜, ゴマ, 芽キャベッ, 大和芋, バナナ, えのき茸, 青菜, トマト, セロリ, しいたけ, 京菜, みつば, 浅草のり, うど, じゃがいも, 白菜浅漬, ニラ, レモン, ハッサ ク, 青忽, ニューヨークレタス, 南瓜, 玉忽, さつまいも, 昆布, 千切大根, 里芋, サラダ菜, グリ ンピース, 茄子, 小麦粉, えび, かまぼこ, 梅焼, スイカ。 以上 82 例

\section{結論}

植物性食品は 3 分間の煮沸，消化管通過によりそれぞれ潜血反応偽陽性率が低下する傾向が強い。 動物性食品は上記低下傾向がほとんど認められない。しかし魚肉類の一部は潜血食に使用できる可能性があ る。したがって潜血食に使用可能食品品種の增加と加熱時間の短縮とが可能であり, これら食品類を表示し た。 
文献

1) 福田寛, 源川孝子： 臨床検査, 7 (2), 150 (1963).

2) 佐藤栄良治：臨床検査, 10(8), 754 (1966).

3）浦壁重治：臨床病理, 10, (1962).

4) 林 康之： 綜合臨床, 12(5), (1963).

5) 厚生連中央病院：臨床栄養, 28 (1 6), (1966).

6) 藤井鴨三：生化学実験法定性篇, 南山堂, 昭和 37 年.

7）金井 泉：臨床検査法提要, 23 版, III-6, (1967).

(本論文は第14回日本栄養改善学会において発表した。)

（受付： 昭和 43 年 1 月 6 日）

\section{F A O 特 報}

\section{通商貿易促進のための食品の規格}

ローマ 2 月 20 日 FAO の理事長 Addke H.

Boerma 氏は50カ国よりなる専門委員会で, 食品の 規格を定めることと, 消費者を保護する諸種の方法 を国際的に統一することによって食糧の供給はヨリ 活発になりヨリ良好な分配が行なわれるので, 食糧 の世界通商を活発ならしめるために, 関税障壁を取 り除くことと, 食糧の経済上の障害を排除すること の必要なことを訴えた。

Boerma 氏は FAO および WHO の支援を受け ている Codex 栄養委員会を10日間に亘って開催し, 食糧の品質, 衛生, 標示扰よび梱包, 食品添加物, 農薬の残存量などその他多くのことがらについて, 適当な規格を作って各国政府に採用させて, 食糧の 諸国間の交易を容易ならしめる計画をたてることを 協議した。

上記の会議の議長で今回限りその席を退くオラン
ダの M.L.L. Dols 博士は, 各国政府は, 今や完全 な食糧法制の制定と各国相互の協力で国々相互間の 食糧流通を容易にすることについてだんだんと関心 を持つようになっているといった。

Boerma 氏はこの会議で次のようにいっている。 すなわち, 消費者の保護のための方策と食糧の規格 化を国際的に実行することによって，追々と各国間 が調和統一されて食糧の移動が追々と自由になるで あろうと。

この委員会は過去 5 年間に亘り粉末乳, バター, チーズ, 砂糖, マーガリン, 油脂などを含む多数の 食品の規格化をなしとげた。そしてこれらの規格を 各国政府に通告してその採用を訴えた。

最近の会議では, ココア, チョコレート, 幾種か の油扰よび脂, 冷凍食品, 野菜缶詰の規格化を協議 し, また残存農薬や, 添加物の許容度の標準化を協 議するであろうし, 食品衛生の一般基準についても 研究しつつある。 